\title{
Erdek Körfezi Karot Çökellerinin Ă̆ır Metal Dağılımı ve Zenginleşme Derecesi
} Distribution of Heavy Metal and Enrichment Degree in Core Sediments from Erdek Gulf

\author{
Tuğçe Nagihan Arslan Kaya ${ }^{* *} \mathbb{D}$, Erol Sarı ${ }^{1} \mathbb{D}$, Mehmet Ali Kurt ${ }^{2} \mathbb{D}$, Dursun Acar ${ }^{3} \mathbb{D}$ \\ ${ }^{1}$ Istanbul Üniversitesi, Deniz Bilimleri ve İşletmeciliği Enstitüsü, Deniz Bilimleri ve Işsletmeciliği Bölümü, \\ 34134 Istanbul \\ ${ }^{2}$ Mersin Üniversitesi, Mühendislik Fakültesi, Çevre Mühendisliği Bölümü, 33343 Mersin \\ ${ }^{3}$ Istanbul Teknik Üniversitesi, Maden Fakültesi, Jeoloji Mühendisliği Bölüm, 34469 İstanbul
}

\begin{tabular}{|c|c|c|c|}
\hline \multirow[t]{2}{*}{ Geliş/Received : 10.05.2019 } & \multicolumn{2}{|c|}{ - Düzeltilmiş Metin Geliş/Revised Manuscript Received : 29.07.2019 } & \multirow{2}{*}{$\begin{array}{l}\bullet \text { Kabul/Accepted : } 15.10 .2019 \\
01.2020\end{array}$} \\
\hline & - Çevrimiçi Yayın/Available online : 15.01.2020 & - Bask1/Printec & \\
\hline
\end{tabular}

Öz: Erdek Körfezi Marmara Denizi'nin güneybatısında yer almaktadır. Ortalama ve maksimum derinliği sırasıyla yaklaşık 34 ve 55 m'dir. Çalışma alanı Marmara Denizi’ndeki diğer körfezlere (İzmit, Gemlik) kıyasla antropojenik kökenli kirleticilere daha az maruz kalmıştır. Körfeze başlıca tatlı su ve çökel taşınımı Karabiga ve Gönen nehirleriyle gerçekleşmektedir. Bu nehirler Gönen ve Biga ilçelerinin evsel, tarımsal ve endüstriyel (seramik fabrikaları ve deri sanayi) kaynaklı atık sularını bünyelerine alarak Marmara Denizi’ne boşalırlar. Bu çalışmada, Gönen Nehri ağzı -16 $\mathrm{m}$ su derinliğinden alınan $174 \mathrm{~cm}$ uzunluğundaki karot çökel örneğinde geçmişten günümüze antropojenik ve/veya doğal kökenli ağır metal miktarındaki değişimler incelenmiştir. Bölgenin ağır metal zenginleşmesi; ağır metal $(\mathrm{Cu}$, $\mathrm{Pb}, \mathrm{As}, \mathrm{Zn}, \mathrm{Cr}$ ve $\mathrm{Co}$ ), tane boyutu ve toplam organik karbon (TOK) analizleri ile değerlendirilmiştir. Elde edilen bulgulara göre, karot boyunca ortalama $\mathrm{Cu}, \mathrm{Pb}, \mathrm{As}, \mathrm{Zn}, \mathrm{Cr}$ ve Co değerleri sırasıyla 16, 68, 10, 26, 111 ve 4 mg.kg-1' ${ }^{-1}$.r. Ortalama çakıl, kum, silt ve kil içerikleri sırasıyla \%0,1, 1, 28,5 ve 70,4'tür. TOK değerleri $\% 0,5$ ile 1,9 arasında değişim göstermektedir. Çalışma alanının ağır metal birikim tarihçesini daha net değerlendirmek için karot boyunca zenginleşme faktörü (EF) değerleri hesaplanmıştır. Karot düşey profili boyunca ortalama EF değerleri; EF-Pb 12,2, EF-As 4,8, EF-Cr 3,3, EF-Zn 1,1, EF-Cu 0,9 ve EF-Co 0,7'dir. Sutherland (2000) zenginleşme faktörü kirlilik derecesi sinıflamasına göre karot çökel örnekleri $\mathrm{Cr}$ ve $\mathrm{As}$ ile orta derecede, $\mathrm{Pb}$ ile de önemli derecede kirletilmiştir. Çalışma alanı $\mathrm{Co}, \mathrm{Cu}$ ve $\mathrm{Zn}$ bakımından kirletilmemiştir. EF-Pb, EF-As ve EF-Cr değerleri körfeze tarımsal ve endüstriyel kökenli (deri sanayi) arıtılmamış antropojenik kaynaklı atık suların deşarj edildiğini göstermektedir.

Anahtar Kelimeler: Ağır metal, antropojenik kirlilik, Gönen Nehri, karot çökeli, zenginleşme faktörü.

\begin{abstract}
The Gulf of Erdek is located in southwest Marmara Sea. Average and maximum depths are around 34 and $55 \mathrm{~m}$, respectively. The study area is less polluted by pollutants of anthropogenic origin than the other gulfs (Izmit, Gemlik) in the Marmara Sea. The main source of fresh water and sediments in the gulf are the Gönen and Karabiga Rivers. These rivers, which receive pollution load from domestic, industries (ceramic factories and leather industry) and agricultural waste water from Gönen and Biga towns, drain into the Marmara Sea. In this study, distribution of historical heavy metal contamination derived from anthropogenic and/or natural origin was investigated in a 174$\mathrm{cm}$ long core sediment collected from the mouth of the Gönen River at $-16 \mathrm{~m}$ water depth. Heavy metal enrichment in the region was determined by analysing heavy metal ( $\mathrm{Cu}, \mathrm{Pb}, \mathrm{As}, \mathrm{Zn}, \mathrm{Cr}$ and $\mathrm{Co})$, grain size and total organic carbon (TOC) contents. According to the results obtained, average $\mathrm{Cu}, \mathrm{Pb}, \mathrm{Zn}, \mathrm{Cr}$ and $\mathrm{Co}$ values in the core are 16, $68,10,26,111$ and $4 \mathrm{mg} \cdot \mathrm{kg}^{-1}$, respectively. The mean distribution of gravel, sand, silt and clay are $0.1,1,28.5$ and $70.4 \%$, respectively. TOC values range between 0.5 and $1.9 \%$. Enrichment factor (EF) was calculated throughout
\end{abstract}


the core to reveal the pollution history of the study area more clearly. Mean EF values through the vertical profile of the core are EF-Pb 12.2, EF-As 4.8, EF-Cr 3.3, EF-Zn 1.1, EF-Cu 0.9, and EF-Co 0.7. Based on Sutherland's (2000) enrichment factor contamination categories, core sediments were moderately contaminated with $\mathrm{Cr}$ and As, and contaminated significantly with $\mathrm{Pb}$. The study area was not contaminated with $\mathrm{Co}, \mathrm{Cu}$ and $\mathrm{Zn}$. The EF-Pb, EF-As and EF-Cr values indicate that untreated anthropogenic waste water with agricultural and industrial origin (leather industry) was supplied into the gulf.

Keywords: Heavy metal, anthropogenic pollution, Gönen River, core sediment, enrichment factor.

\section{GíRIş}

Türkiye'de ve dünyada teknolojiye olan ihtiyacın artması sanayileşme, endüstrileşme ve kentleşmeyi zorunlu kılmıştır. Gelişme ve sanayileşmeyle birlikte birçok sanayi kuruluşu daha çok hammadde kullanımına gereksinim duymuştur. Bu ihtiyaçları karşılamak için doğal kaynaklar hızlı bir şekilde insan eliyle tahribata uğramış ve doğal ekoloji gün geçtikçe daha çok zarar görmüştür (Akyüz vd., 2007; Hallı vd., 2014). Sanayi üretimi, enerji kaynakları, madensel faaliyetler, tarımsal aktiviteler, evsel ortamlar ve diğer kirletici kaynaklardan ortaya çıkan atık sular ve/veya kimyasalların çeşitli yollarla alıcı ortama verilmesi; akarsu, göl ve denizlerin hızla kirletilmesine neden olmuştur (Sarı, 2008).

Sanayi kuruluşlarının birçoğu üretim aşamasında ve sonrasında çevreye toksik etki oluşturabilecek düzeyde ağır metal içeren kimyasal ürünleri kullanmaktadır. Ağır metaller sucul ortama endüstriyel ve tarımsal kökenli kirleticilerin yanı sıra doğal süreçler (kayaçlardaki minerallerin çözünmesi) ile de geçerler. Demir, Zn, $\mathrm{Cu}$ ve $\mathrm{Mn}$ gibi bazı ağır metaller gerekli (faydalı) besinlerken, $\mathrm{Cd}, \mathrm{Hg}$ ve $\mathrm{Pb}$ gibiler ise gerekli olmamakla beraber yüksek miktardaki bileşenleri toksik etki oluşturmaktadır (Tchounwou vd., 2012; Mohsen vd., 2019). Ağır metaller deniz tabanında minerallerin ve karbonatların kristal yapılarına, organik madde ve killerin üzerlerine absorbe olarak depolanırlar (Çağatay vd., 2006). Deniz tabanından alınan karot çökellerinin jeokimyasal ve sedimantolojik yöntemlerle incelenmesiyle denizlerin ağır metal tarihçesi ve geçirdikleri jeolojik süreçler hakkında önemli bilgilere ulaşılmaktadır (Çağatay vd., 2002; Sarı vd., 2013).

Erdek Körfezi, Marmara Denizi'nin diğer körfezlerine (Gemlik, İzmit) kıyasla sanayi ve endüstri yoğunluğunun az olduğu bir bölgedir. Erdek Körfezi ve civarında yüzey çökellerinin mevcut kirlilik durumunu ortaya çıkarmaya yönelik araştırmalar yapılmıştır (Balkıs ve Çağatay, 2001; Mülayim vd., 2012; Yümün vd., 2019). Fakat çalışma alanının kirlilik tarihçesi ve çökel kalitesine yönelik literatürde son 10 yılda ayrıntılı bir çalışma bulunmamaktadır. Balkıs ve Çağatay (2001), Erdek Körfezi yüzey çökellerinde $\mathrm{Fe}, \mathrm{Mn}, \mathrm{Pb}, \mathrm{Cu}, \mathrm{Ni}, \mathrm{Cr}, \mathrm{Zn}$ ve $\mathrm{Hg}$ içeriklerini tespit ederek, çökellerdeki metal zenginleşmesinin büyük oranda kara kökenli doğal ve az miktarda da antropojenik kaynaklı kirleticilerin neden olduğunu tespit etmiştir. Ayrıca, araştırmacılar Erdek Körfezi'nde yüksek konsantrasyondaki Pb, $\mathrm{Zn}, \mathrm{Cu}$ ve Hg'nın ana kaynağını nehirlerin drenaj alanlarındaki mineralize olmuş kayaçlardan taşıdıkları, benzer bir şekilde $\mathrm{Cu}$, Ni ve Cr'daki yüksek metal değerlerinin ofiyolitik ve volkanik kökenli mafik ve ultramafik kayaçlardan kaynaklandığını belirlemiştir. Mülayim vd. (2012), Erdek ve Bandırma Körfezleri'nde 1-30 m arası değişen su derinliklerinden aldıkları yüzey çökellerinde Al, Fe, Mn, Ni, Cu, Zn, Cr, Cd, Pb ve Hg içeriklerini Krauskopf (1979) şeyl değerleri ile kıyaslayarak, çökellerdeki metallerin zenginleşme boyutunu tartışmıştır. Her iki körfezde $\mathrm{Pb}$ (20 mg. $\left.\mathrm{kg}^{-1}\right)$ ve Cd (0,2 mg. $\left.\mathrm{kg}^{-1}\right)$ içerikleri şeyl değerlerinden yüksek gözlenirken çalışılan diğer metallerin (Ni, $\mathrm{Cu}, \mathrm{Zn}, \mathrm{Cr}$ ve $\mathrm{Hg}$ ) içerikleri düşük gözlenmektedir. 
Literatür çalışmaları yüzey çökellerinde yapıldığından kısıtlı bir zaman aralığını kapsamaktadır. Yüzey çökel örnekleri ile metal zenginleşme boyutu değerlendirilirken bölgenin daha eski metal değerlerine ulaşılmamakta ve dolayısıyla paleokirlilik boyutu net olarak ortaya çıkarılmamaktadır. Bumakaleilekarotçökellerinde sedimantolojik ve jeokimyasal analizler yapılarak geçmişten günümüze metal birikimi ortaya çıkarılmış ve körfezin $\mathrm{Cu}, \mathrm{Pb}, \mathrm{As}, \mathrm{Zn}, \mathrm{Cr}$ ve $\mathrm{Co}$ ile zenginleşme derecesi boyutlandırılmıştır. $\mathrm{Bu}$ kapsamda elde edilen bulgular ile literatürdeki boşluk tamamlanmıştır. Çalışmanın amacına uygun olarak Erdek Körfezi'nden -16 m su derinliğinden $\quad\left(40^{\circ} 20^{\prime} 0.60^{\prime \prime} \mathrm{K}, \quad 27^{\circ} 38^{\prime} 4.20^{\prime \prime} \mathrm{D}\right)$ alınan karot örneğinde (GD1) metal analizi, toplam organik karbon (TOK), toplam inorganik karbon (TIK) ve tane boyu analizleri yapılmıştır. Ayrıca zenginleşme faktörü (EF) hesaplanarak ortamın kirlilik derecesi boyutlandırılmıştır. Erdek Körfezi'nin çökel niteliği ve kirlilik tarihçesi ortaya çıkarılmıştır.

\section{MATERYAL ve METOT}

\section{Çalışma Alanı ve Örnekleme}

Marmara Denizi toplam $11500 \mathrm{~km}^{2}$ lik alana ve $3378 \mathrm{~km}^{3}$ 'lük bir hacme sahip olup, maksimum uzunluğu (Gelibolu-İzmit) $276 \mathrm{~km}$, maksimum genişliği 76 km'dir (Ünlüata vd., 1990; Yüce ve Türker, 1991; Akkaya, 2004). Marmara Denizi iki tabakalı su sistemine sahiptir. Üstte düşük yoğunluktaki (tuzluluk 22 ppt) Karadeniz kökenli su tabakası, altta ise yüksek yoğunluktaki (tuzluluk 36 ppt) Akdeniz kökenli su tabakası bulunur (Çağatay vd., 2003). Erdek Körfezi, Marmara Denizi'nin güneybatısında bulunmakta ve körfezin doğusunda Kapıdağ Yarımadası, kuzeyinde Avşa, Paşalimanı ve Marmara Adaları yer almaktadır (Şekil 1). Bölgede seramik endüstrisi, deri sanayi ve tarımsal aktiviteler dışında büyük ölçüde kirliliğe katkıda bulunacak kaynaklar bulunmamaktadır. Ancak tarımda kullanılan gübre ve ilaçlar akarsularla bu körfeze taşınmaktadır (Çağatay vd., 2006). Körfezi besleyen iki temel akarsu (Karabiga ve Gönen) mevcuttur (Şekil 2). Karabiga Nehri 97 ton/y1l ve Gönen Nehri 78 ton/yı1 askıda çökel taşımaktadır (EİE, 1993). Bu akarsuların drenaj alanları sirasiyla 2100 ve 1200 $\mathrm{km}^{2}$ 'dir (Balkıs ve Çağatay, 2001).
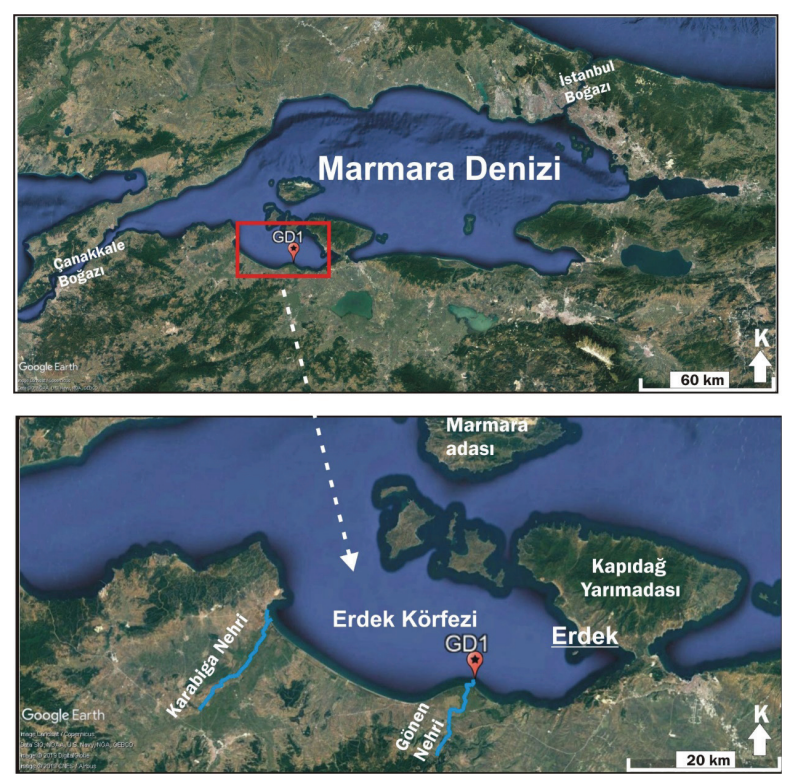

Şekil 1. Çalışma alanında karot yerini gösteren yer bulduru haritas1.

Figure 1. Location map showing the study area and core site.

Biga, Çan ve Gönen ilçelerinde çok sayıda $\mathrm{Pb}, \mathrm{Mn}, \mathrm{Fe}, \mathrm{Hg}, \mathrm{Cu}$ ve $\mathrm{Zn}$ maden yatakları ve cevherleşme zonları bulunmaktadır (Şekil 2). Biga Yarımadası'nda Ni, Cr ve Co yüksek temel (background) değerleri içeren mafik ve ultramafik kayaçlar yer almaktadır (Çağatay vd., 2006). Karabiga ve Gönen Nehri'nin denize döküldüğü alan Holosen yaşlı alüvyon çökellerden oluşmakta ve bu çökeller bölgenin en genç birimini temsil etmektedir. Nehirlerin beslenme alanında Neojen yaşı karasal çökeller, $\mathrm{Pb}$ ve $\mathrm{Cu}$ mineral zonları içeren andezit kayaçlar, Permo-Triyas yaşlı Çal Formasyonu ve Geç Triyas yaşlı Hodul 
Formasyonu yüzeylenmektedir. Çal Formasyonu spilitik bazalt, aglomera ve çamurtaşından oluşurken, Hodul Formasyonu arkozik kumtaş1, moloz akıntısı, silttaşı, bazik (spilit) kayalar ve bunlara eşlik eden kireçtaşlarından oluşmaktadır (Karabulut, 2004).

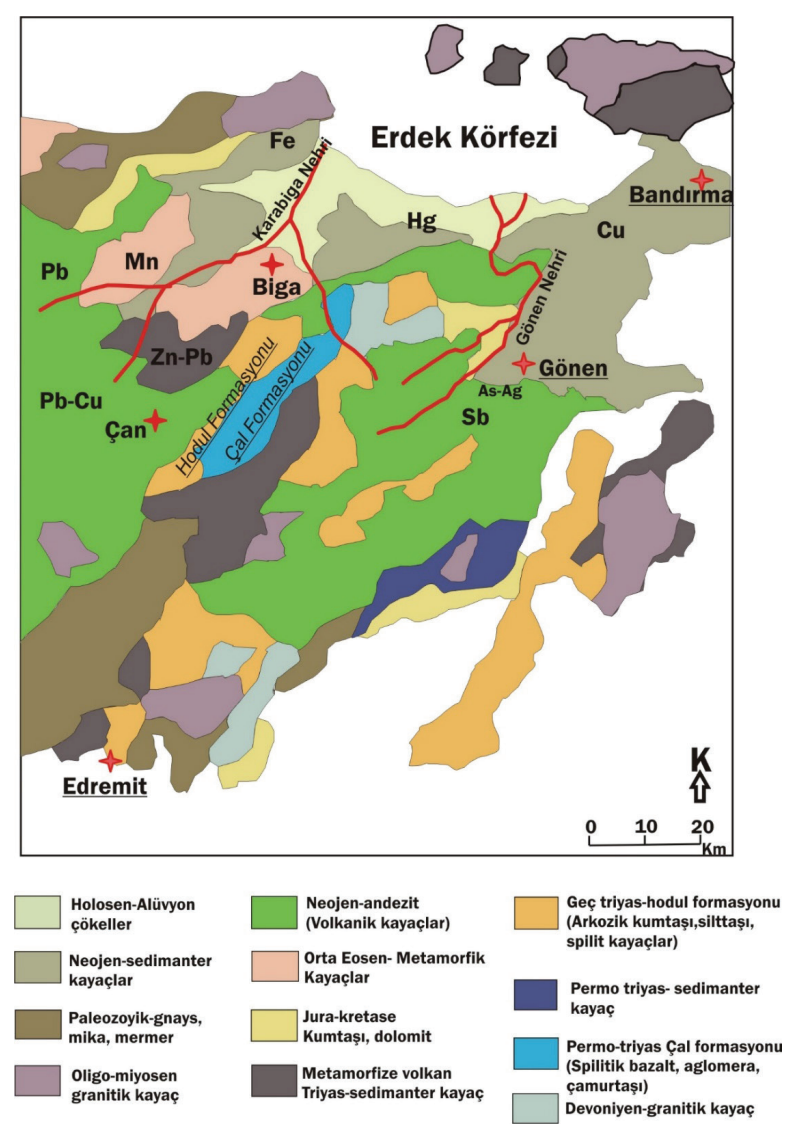

Şekil 2. Erdek Körfezi ve çevresinin mineral zon, drenaj sistemi ve kayaçlarını gösteren jeolojik haritası (Ternek vd., 1987; Akyüz, 1995; Balkıs ve Çağatay, 2001'den değiştirilerek).

Figure 2. Geological map showing mineral zones, drainage system and lithology of Erdek Gulf and its surroundings (modified from Ternek et al., 1987; Akyüz, 1995; Balkıs and Çağatay, 2001).

ALEMDAR II R/V gemisi ile 2014 y1l Temmuz ayında Erdek Körfezi -16 m su derinliğinden, $174 \mathrm{~cm}$ uzunlukta karot çökeli alınmıştır (Şekil 1). Alınan karot çökeli İstanbul Üniversitesi, Deniz Bilimleri ve İşletmeciliği Enstitüsü soğuk deposunda $(-5$ ile +5$)$ analiz edilinceye kadar bekletilmiştir. GD1 karotu uzunlamasına iki eş parçaya bölünerek yüzeyi temizlenmiş, fotoğraflanmış ve ardından litolojik tanımlaması yapılmıştır. Tane boyu analizi için karot çökelinin yarısı 2'şer cm aralıklarla örneklenirken, diğer yarısı jeokimyasal analizler için 0-30 cm aras1 $1 \mathrm{~cm}, 30-60 \mathrm{~cm}$ arası $2 \mathrm{~cm}, 60$ $100 \mathrm{~cm}$ arası $5 \mathrm{~cm}$ ve $100 \mathrm{~cm}$ altı için $10 \mathrm{~cm}$ alt örneklemeleri yapılmıştır. Jeokimyasal analizler için örnekler $50^{\circ} \mathrm{C}$ de kurutulmuş ve agat havanda ögütülmüştür.

\section{Tane Boyu Analizi}

Çökelin tane boyu içeriği ve dağılımı, örneğin istatistiksel anlamda tanımlanması, taşıyıcı ajanın gücü hakkında fikir vermesi, depolanma ortamının incelenmesi açısından önemlidir (Hall1, 2014). Ayrica tane boyu ile metal birikim arasında ters bir orantı olup, yüzey alanı arttıkça çökelin metal tutma kapasitesi artmaktadır. Tane boyu analizi İstanbul Üniversitesi, Deniz Jeolojisi laboratuvarında yapılmıştır. Bu çalışmada Galehouse (1971) ve McManus (1991) metodunu kullanarak, çökel de bulunan çakıl, kum, silt ve kil miktarları belirlenmiştir. $\mathrm{Bu}$ metodun ayrıntılı açıklaması Hallı (2014) yüksek lisans tezinden verilmiştir. $\mathrm{Bu}$ teze göre: çökelde bulunan çözünebilir tuzlar, kil boyutundaki materyalin topaklanmasına (tanelerin bir araya gelip çökmesi) neden olarak analizi hatalı sonuca götürür. Bu nedenle örnekler öncelikle tuzlardan arındırılmak amacıyla saf suda bekletilmiş, sifonlama ile birkaç kez yıkanmıştır. Islak örnek $100^{\circ} \mathrm{C}$ etüvde kurutularak toplam ağırlığı kayıt edilerek, \%10'luk kalgonlu saf suda 24 saat bekletilmiştir. Kalgonlu sslak örnek 0,063 mm'lik elek üzerinde musluk altında yıkanarak kaba taneli fraksiyonların (çakıl+kum), ince taneli (silt+kil) çökellerden ayrılması sağlanmıştır. Bu yıkama işlemini yaparken eleğin altına toplayıcı 
bir kap konulmuş, yeteri miktarda ince taneli çökel içeren sıvı toplandıktan sonra, eleğin üzerindeki kaba tanelilerin yıkanmasına devam edilmiştir. Yıkama işlemi eleğin altından akan suyun berrak oluşuna kadar sürdürülmüştür. Eleğin üzerindeki kaba taneli kısım bir kaba aktarılarak, etüvde 100 ${ }^{\circ} \mathrm{C}$ de kurutulmuş. Kurutulan örnek tartıld1ktan sonra; çakı1 ve kum boyutu malzeme elek takımı (Retsch, As 200 marka) ile silt ve kil boyutu malzemede bilgisayar kontrollü lazer saçılımlı Sedigraph 5120 aleti ile ölçülmüştür.

\section{Toplam Organik Karbon ve Toplam İnorganik Karbon Analizleri}

Toplam organik karbon (TOK) ve toplam inorganik karbon (TIKK) analizleri İstanbul Üniversitesi, Deniz Jeolojisi laboratuvarında yapılmıştır. TOK analizi, Walkley Black yöntemi (Gaudette vd., 1974; Loring ve Rantala, 1992) ile yapılmıştır. Bu işlem organik maddenin potasyum dikromat ile oksidasyonunu ve demir amonyum sülfat ile titre olmasını içerir. TİK analizi, Loring ve Rantala (1992) tarafindan önerilen metoda göre yapılmıştır. Metot, örneklerin $4 \mathrm{~N} \mathrm{HCl}$ ile muamele edilip çıkan $\mathrm{CO}_{2}$ gazının hacimsel olarak ölçülmesi prensibine dayanır.

\section{Metal Analizi}

Karot çökellerinin metal içerikleri; toplam çözünürleştirme işleminden sonra indüktif eşleşmiş plazma ve kütle spektrometresi (ICP-MS, Agilent 7500ce) kullanılarak Mersin Üniversitesi, Çevre Mühendisliği Bölümü'nde belirlenmiştir. Toplam çözünürleştirme için kurutulmuş ve ögütülmüş çökel örneklerinden yaklaşı $0,2 \mathrm{~g}$ tartılmıştır. Çözünürleştirme yöntemi kapalı sistemde hidroflorik asit ve kral suyu (3:1 oranında hidroklorik asit ve nitrik asit) karışımında, sabit basınç ve sıcaklıkta $\left(180^{\circ} \mathrm{C}\right)$ mikrodalga firında (CEM MARS 240/50) gerçekleştirilmiştir. Analizlerin doğruluğu SRM 2710 no'lu referans materyal ile test edilmiştir.

\section{Zenginleşme faktörü}

Zenginleşme faktörü (EF) antropojenik kökenli kirlilik derecesini ve boyutunu göstermede kullanılan bir parametredir (Sakan vd., 2009; Malvandi, 2017). Ölçümü yapılan elementlerin ve temel değerlerin $\mathrm{Al}$ ve $\mathrm{Fe}$ gibi (Karbassi vd., 2008; Amin vd., 2009) referans elementlere oranlanmasıyla belirlenir. $\mathrm{Bu}$ çalışmada EF değerleri aşağıdaki formül kullanılarak hesaplanmıştır. Eşitlik (1)'de referans element olarak Al tercih edilmiştir.

$$
E F=\frac{(X / A l)_{\text {çökel }}}{(X / A l)_{\text {background }}}
$$

Hesaplamada Krauskopf(1979) şeyl değerleri background (temel) değerler olarak kullanılmıştır. Eşitlikte $(\mathrm{X} / \mathrm{Al})_{\text {çökel, }}$ örnekteki metalin alüminyuma oran1, $(\mathrm{X} / \mathrm{Al})_{\text {background }}$ ise şeyldeki metalin $\mathrm{Al}$ ile oranıdir.

$\mathrm{Bu}$ çalışmada elde edilen zenginleşme faktörü verileri Sutherland (2000) siniflamasina göre değerlendirilmiştir. Buna göre $\mathrm{EF} \leq 2$ ağır metal zenginleşmesinin minimum değerden küçük olduğu; $2<\mathrm{EF}<5$ orta derece zenginleşme; $5<\mathrm{EF}<20$ önemli derecede zenginleşme; $20<\mathrm{EF}<40$ çok yüksek miktarda zenginleşme ve $E F>40$ aşırı miktarda zenginleşme olarak yorumlanmaktadir.

\section{BULGULAR}

\section{Karot Litolojisi ve Tane Boyu Dağılımı}

Körfezin sığ kesiminden alınan (-16 m) GD1 karot çökel örneği $174 \mathrm{~cm}$ uzunluğunda olup, karotun ilk 98 cm'yi açık grimsi kahverengi çamurdan, alt seviyeleri $(98-174 \mathrm{~cm})$ koyu gri-kahverengi çamurdan oluşmaktadır (Şekil 3). Karotun bazı seviyelerinde yer yer laminalı birimler olduğu radyografik görüntülerle tespit edilmiştir (Şekil 
3). Ayrıca karot yüzeyinde biyojenik kavkı ve kavkı kırıkları da gözlemlenmiştir. Karotun üst seviyesinde $(0-6 \mathrm{~cm})$ kaba kum boyutu malzemelerin (çakıl ve kum) artışı $(\% 3,5)$ kavkı ve kavkı kırıklarından kaynaklanmaktadır (Şekil 4). GD1 karotu genel olarak kil fraksiyonundan oluşmaktadır (Şekil 4). Karot boyunca ortalama çak1l, kum, silt ve kil içerikleri sırasıyla \%0,1, 1, 28,5 ve 70,4 'tür. Karotun tane boyutu dağılımında kil içeriğinin \%60,4 ile \%81,7 arasında değişmesi, Gönen Nehri'nin çalışma alanına süspansiyon halde daha çok kil malzemesi taşıdığını göstermektedir.

\begin{tabular}{|c|c|}
\hline $\begin{array}{r}\text { Karot } \\
\text { Karot } \\
\text { Derinlik(cn } \\
\end{array}$ & $\begin{array}{l}\text { Derinlik: }-16 \mathrm{~m} \\
\text { Enlem: } 40^{\circ} 00^{\prime} 0.600^{\prime \prime} \\
\text { Boylam: } 27^{\circ} 38^{\prime} 4.20^{\prime \prime} \mathrm{D}\end{array}$ \\
\hline 0 & \multirow{3}{*}{$\begin{array}{l}\text { Kavkı ve kavkı kırıları } \\
\text { Açık grimsi kahverengi çamur }\end{array}$} \\
\hline 10 & \\
\hline 20 & \\
\hline 30 & \multirow[b]{5}{*}{$\begin{array}{l}\text { Koyu gri-siyah laminalı } \\
\text { açık grimsi kahverengi çamur }\end{array}$} \\
\hline 40 & \\
\hline 50 & \\
\hline 60 & \\
\hline 70 & \\
\hline 80 & \\
\hline 90 & \\
\hline 100 & \\
\hline 110 & $\downarrow$ \\
\hline 120 & \\
\hline 130 & $\begin{array}{l}\text { Koyu gri-siyah laminalı } \\
\text { gri-kahverengi çamur }\end{array}$ \\
\hline 140 & \\
\hline 150 & $\downarrow$ \\
\hline 170 & $\begin{array}{l}\text { 2-3 mm kalınlığında siyah bant } \\
\text { seviyeli gri-kahverengi çamur }\end{array}$ \\
\hline
\end{tabular}

Şekil 3. GD1 karot çökelinin radyografik görüntüsü ve litolojisi.

Figure 3. Radiographic image and lithology of GD1 core sediment.

\section{Çökel Jeokimyası}

GD1 karotunda TİK değeri \%5,1 ile \%17,1 arasında değişmekte olup, ortalama TİK değeri \%10,3'tür. Çalışılan çökel karotunun ilk 37 cm'inde TİK değeri yüksek (>\%10) iken, bu seviyeden itibaren karot tabanına doğru TİK değerinin azaldığ 1 tespit edilmiştir (Şekil 5). TOK değeri GD1 karotunda $\% 0,5$ ile \%1,9 arasında değişmektedir. Ölçümü yapılan bütün seviyelerde ortalama TOK değeri \%1,4 olarak hesaplanmıştır. GD1 karotunun ağır metal içeriklerinin karot boyunca değişimleri Şekil 5'te verilmiştir. Çökel karotundaki Al, $\mathrm{Cr}, \mathrm{Pb}, \mathrm{Cu}, \mathrm{Zn}, \mathrm{As}$ ve Co konsantrasyonlarının değişim aralıkları sırasıyla 10433-49611, 21430, 48-88, 10-20, 15-36, 4-25 ve 3-5,3 mg.kg${ }^{1}$ dir. Ortalama $\mathrm{Al}, \mathrm{Cr}, \mathrm{Pb}, \mathrm{Cu}, \mathrm{Zn}, \mathrm{As}$ ve $\mathrm{Co}$ konsantrasyonu 26587, 111,7, 68,4, 16, 26,4, 9,7 ve $3,9 \mathrm{mg} \cdot \mathrm{kg}^{-1}$ olarak belirlenmiştir. Metal dağ $11 \mathrm{~mm}$ profili incelendiğinde karotun üst seviyesinde (0$50 \mathrm{~cm}$ ) metal konsantrasyonlarının alt seviyelere kıyasla daha yüksek olduğu gözlenmektedir (Şekil 5). Özellikle $\mathrm{Pb}, \mathrm{Zn}$ ve $\mathrm{Cr}$ konsantrasyonunda belirgin bir değişim görülmektedir (Şekil 5).

\section{SONUÇLAR ve TARTIŞMA}

\section{Karot Çökel Niteliği ve Ağır Metal Kirlilik Tarihçesi}

Karot boyunca ölçümü yapılan ağır metal verileri kullanılarak çalışma alanının çökel niteliği EF verileriyle aydınlatılmıştır. GD1 karotunun ortalama EF değerleri büyükten küçüğe doğru sirasiyla EF-Pb 12,2, EF-As 4,8, EF-Cr 3,3, EF-Zn 1,1, EF-Cu 0,9 ve EF-Co 0,7'dir. Karot çökelinin düşey profili boyunca $\mathrm{Cu}$ ve $\mathrm{Co}$ bir zenginleşme gözlenmezken, 0 ile $40 \mathrm{~cm}$ arası EF$\mathrm{Zn}$ değerinde belirgin bir artış olmasına rağmen sadece iki seviyede $(12,5$ ve $27,5 \mathrm{~cm})$ eşik değeri $(\mathrm{EF}>2)$ aşmıştır (Şekil 6). Bu seviyeden itibaren EF-Zn değeri azalmakta ve kirletici unsur olarak görülmemektedir. Krom, As ve $\mathrm{Pb}$ EF değerleri karot boyunca genellikle 2'nin üzerinde değerler 


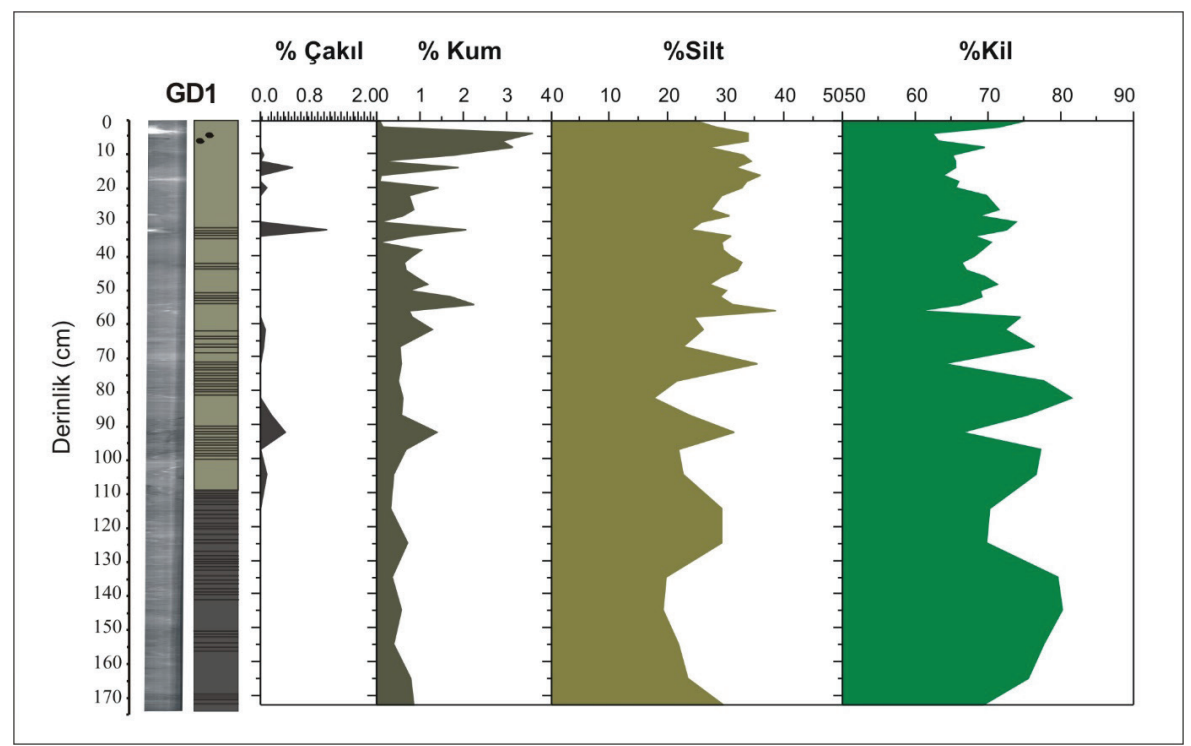

Şekil 4. GD1 karotu çakı1l, kum, silt ve kil dağılımı.

Figure 4. Gravel, sand, silt and clay distribution in core GD1.

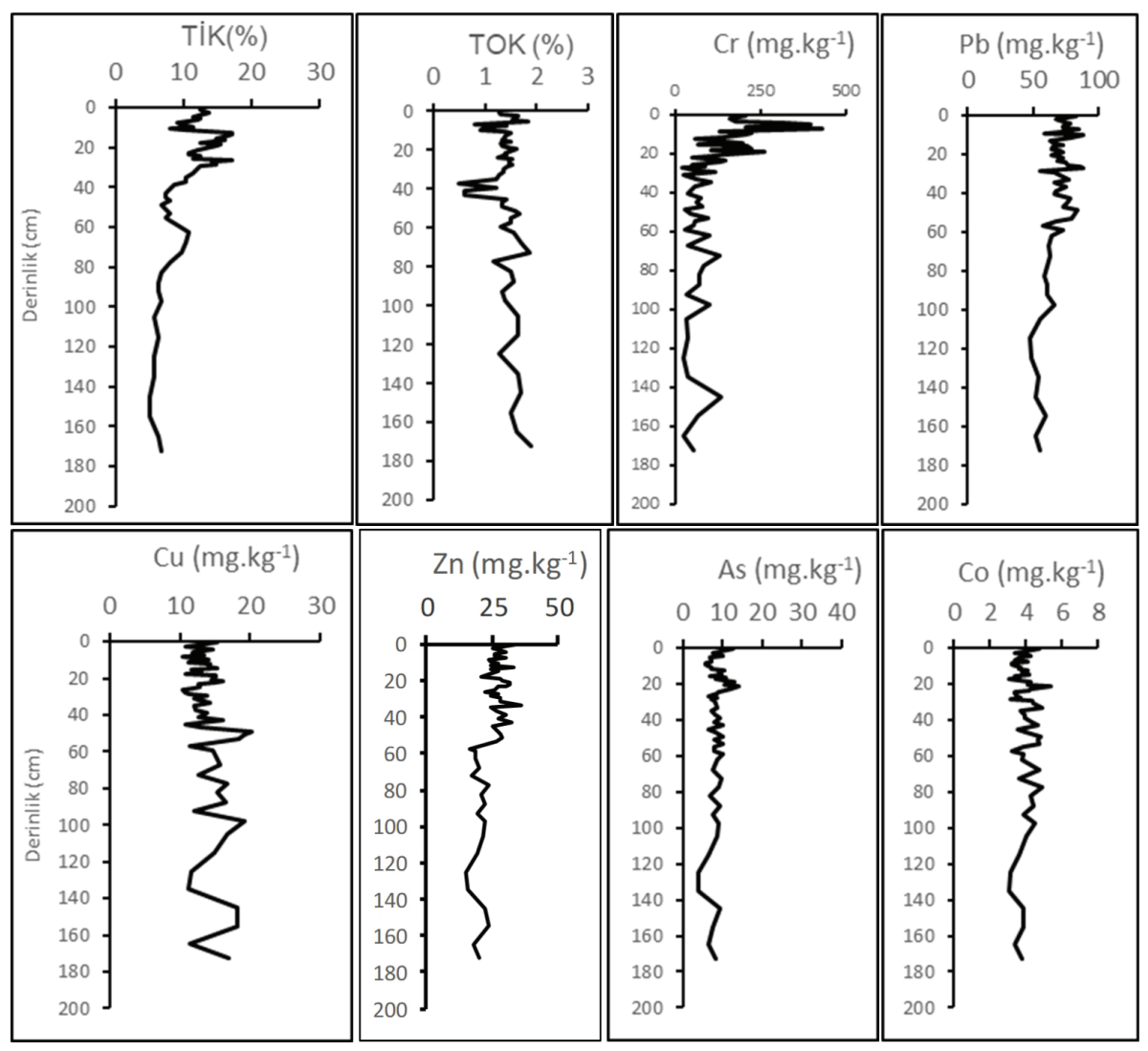

Şekil 5. GD1 karotu düşey derinlik boyunca TİK, TOK, As ve ağır metal dağılımları.

Figure 5. TIC, TOC, As and heavy metal distributions in GDl core through vertical depth. 
almaktadır. Bölgenin jeolojisi dikkate alındığında As ve Pb'daki bu ciddi zenginleşmenin boyutu sadece antropojenik girdiler ile değil aynı zamanda doğal girdilerinde etkili olduğu karot tabanındaki yüksek EF değerleriyle desteklenmektedir. Erdek Körfezi ve çevresinde $\mathrm{As}$ ve $\mathrm{Pb}$ mineral zonları ve mafik, ultramafik kayaçların bulunması, karot tabanında yüksek EF-As ve EF-Pb zenginleşmesi, doğal süreçlerin $\mathrm{As}$ ve $\mathrm{Pb}$ zenginleşmesi üzerinde etkili olduğunu göstermektedir.
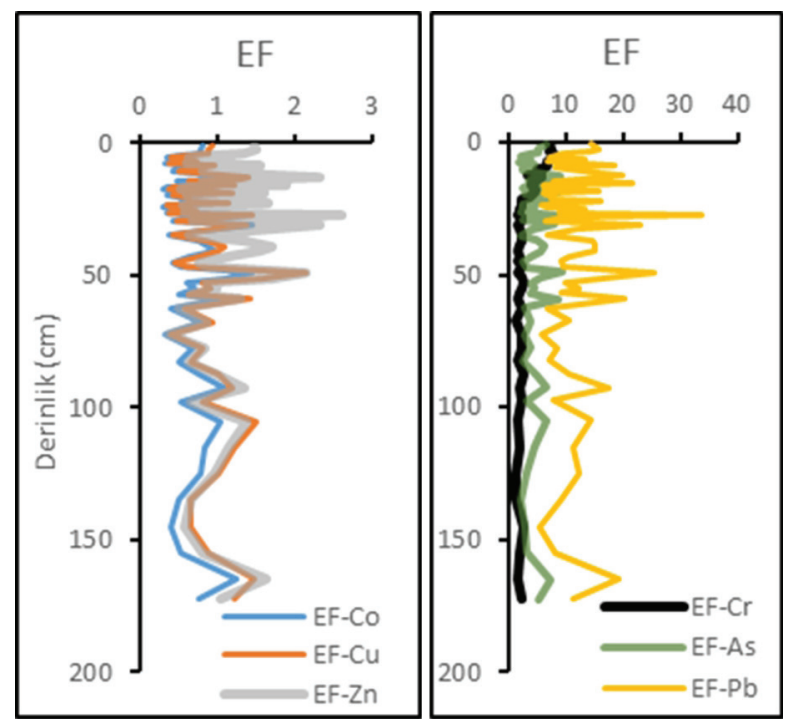

Şekil 6. GD1 karotu düşey profil boyunca zenginleşme faktörü (EF) dağılımı.

Figure 6. Enrichment factor (EF) distribution in GD1 core through the vertical profile.

Karotun üst seviyesindeki çökeller yakın zamanda depolandı̆̆ 1 için genelde güncel kirliliği gösterir. GD1 karotunun 0-12 cm arasinda $\mathrm{Cr}$ değerleri oldukça yüksektir. Kromdaki bu artış Gönen ilçesindeki irili ufaklı deri işleme tesislerinden kaynaklanmaktadır. Özellikle deri işleme tesislerinden arıtılmamış atık suların Gönen Nehri'ne deşarj edilmesi ile çalışma alanı $\mathrm{Cr}$ açısından zenginleşmiştir. Sarı (2008), Gönen ve Biga Nehir çökellerindeki yüksek Cr değerlerinin deri işleme tesislerinden kaynaklandığını ileri sürmüştür. $\mathrm{Cr}$ ile $\mathrm{Al}$ arasında gözlenen orta düzeydeki korelasyon katsayısı $(\mathrm{r}=0,6), \mathrm{Cr}$ elementinin zenginleşmesinde kara kaynaklı (litojenik) malzemelerinde etkisinin olduğunu göstermektedir. Co ile $\mathrm{Zn}$ ve Co ile As çiftleri arasinda orta düzeyde korelasyon katsayısı $(\mathrm{r}=0,6)$ tespit edilirken, $\mathrm{Co}$ ile $\mathrm{Cu}$ arasinda nispeten daha yüksek korelasyon katsayısının ( $\mathrm{r}=0,7)$ bulunması; bu ağır metallerin aynı kaynaktan ve/veya aynı süreçlerden etkilendiğini göstermektedir (Çizelge 1). Yüksek $\mathrm{Pb}$ ve $\mathrm{Zn}$ içeren sedimanter kayaçların aşınma ürünleri muhtemel Karabiga Nehri ile denizel ortama taşınmakta ve depolanmaktadır (Şekil 2). Pb ile $\mathrm{Zn}$ arasında gözlenen orta düzeyde korelasyon katsayısı $(\mathrm{r}=0,6)$ olası $\mathrm{Pb}$ ile $\mathrm{Zn}$ zenginleşmesinde litojenik kaynakların etkili olduğunu göstermektedir. Karotun üst seviyelerindeki yüksek ağır metal değerleri antropojenik kirleticiler ile temsil edilirken, karotun alt seviyelerindeki genel olarak düşük metal değerleri endüstriyel dönem öncesini ve muhtemel daha eski dönemleri yansitmaktadır (Sar1 vd., 2018).

Bölgede antropojenik kirliliğe etki edecek muhtemel kaynaklar mevcut olup bunlar; (1) seramik endüstrisi, (2) deri işleme tesisleri (3) tarımsal ilaçlar ve gübrelerdir. Seramik imal eden tesisler çevreye (havaya, suya ve toprağa) toz ve partikül halinde kirleticilerin salınmasına sebep olmaktadır. $\mathrm{Bu}$ kirleticilerden suya salınanlar; mineral bileşenler (çözünemez partikül madde), küçük miktarlarda çeşitli organik materyaller ve ayrıca bazı ağır metaller içermektedir (MET Referans Dokümanı BREF, 2007). Bölgenin bir diğer önemli ağır metal kaynağı tarımda kullanılan pestisitler ve ilaçlardır. Pestisit kullanımı 19. yüzyılın son dönemlerinde yaygın olarak kullanılmaya başlanmıştır (Yıldız vd., 2005). İdeal bir pestisit kullanımı sadece hedef organizmay1 etkilerken, yüksek dozda ve bilinçsizce kullanımı ekosistemi etkileyebilmekte ve kirliliğe neden olabilmektedir. 
Çizelge 1. Elementlerin pearson korelasyon analizi.

Table 1. Pearson correlation matrix of elements.

\begin{tabular}{cccccccc}
\hline & Al & $\mathbf{C r}$ & $\mathbf{Z n}$ & $\mathbf{C o}$ & $\mathbf{A s}$ & $\mathbf{P b}$ & $\mathbf{C u}$ \\
\hline $\mathbf{A l}$ & 1 & & & & & & \\
$\mathbf{C r}$ & 0,6 & 1 & & & & & \\
$\mathbf{Z n}$ & 0,1 & 0,3 & 1 & & & & \\
$\mathbf{C o}$ & 0,1 & $-0,1$ & 0,6 & 1 & & & \\
$\mathbf{A s}$ & 0,1 & 0,1 & 0,5 & 0,6 & 1 & & \\
$\mathbf{P b}$ & 0,1 & 0,3 & 0,6 & 0,3 & 0,3 & 1 & \\
$\mathbf{C u}$ & 0 & $-0,1$ & 0,2 & 0,7 & 0,5 & $-0,1$ & 1 \\
\hline
\end{tabular}

\section{Erdek Körfezi Metal Sonuçlarının Diğer Çalıșmalar ile Karșılaștırılması}

Çalışma kapsamında GD1 karot çökeli metal değerleri daha önceki çalışmalar ile karşılaştırılması yapılmıştır (Çizelge 2). Elde edilen sonuçlara göre Erdek Körfezi $\mathrm{Cr}$ değerleri (21-430 mg. $\mathrm{kg}^{-1}$ ) Çizelge 2'deki diğer bölgelere göre daha yüksektir. Kromun diğer körfezlere göre bu kadar yüksek çıkması Gönen Nehri drenaj alanındaki deri işleme tesislerinin atık sularından kaynaklanmaktadır (Sarı, 2008). Gönen ve Karabiga nehir çökellerinin yüksek $\mathrm{Cr}$ ile karakterize olduğu, Cr'un çökellerde organik ve Fe-Mn oksihidroksitlerde bulunduğu Sarı (2008) tarafından belirlenmiştir. Çizelge 2 incelendiğinde mevcut çalışmada $\mathrm{Zn}$ ve Co sırasıyla 15-36 mg.kg- ve 3-5.3 mg. $\mathrm{kg}^{-1}$ aralığında değişirken, diğer çalışmalardaki $\mathrm{Zn}$ ve Co değerleri oldukça yüksek konsantrasyon aralığında kalmaktadır. Çalışma alanındaki As verileri İzmit ve İzmir Körfezleri ile benzer sonuçlar göstermektedir (Çizelge 2). Kurşun konsantrasyonu genel olarak Erdek, Bandırma, İzmit ve İzmir körfezlerinde yüksek gözlenmektedir. İzmit Körfezi yarı kapalı bir havza olması ve çevresinin sanayi ve endüstri kuruluşları ile çevrili olması nedeniyle litojenik ve/veya antropojenik kaynaklı $\mathrm{Pb}$ ile kirletilme olasılığ1 oldukça yüksektir. Mevcut çalışmada $\mathrm{Pb}$ karot yüzeyinde zenginleşmesi kirliliğinin antropojenik kaynaklı olduğunu göstermektedir. Pekey vd. (2004), İzmit Körfezi çökellerinin Pb ile kirletildiğini ve kökeninin endüstriyel atık suyun yanı sıra motorlu araçlardan kaynaklandığını belirtmiştir. Ortalama şeyl değerine göre Erdek Körfezi çökellerinin bakırca bir zenginleşme göstermediğini söyleyenebilir. Bakır, mevcut çalışmada 10-20 mg. $\mathrm{kg}^{-1}$ arası değerler alırken, bölgede daha önceden yapılan çalışmada (Balkıs ve Çağatay, 2001) nispeten daha yüksek $\mathrm{Cu}$ değerleri belirlenmiştir.

Çizelge 2. Erdek Körfezi metal değerlerinin literatürdeki metal değerleri ile karşılaştırılması (mg.kg-1).

Table 2. Comparison of Erdek Gulf metal values with metal values in the literature ( $\mathrm{mg}^{-\mathrm{kg}^{-1}}$ ).

\begin{tabular}{|c|c|c|c|c|c|c|c|c|c|c|c|c|}
\hline \multirow{2}{*}{ Lokasyon } & \multicolumn{2}{|c|}{$\mathrm{Cr}$} & \multicolumn{2}{|c|}{$\mathbf{Z n}$} & \multicolumn{2}{|c|}{ Co } & \multicolumn{2}{|c|}{ As } & \multicolumn{2}{|c|}{$\mathbf{P b}$} & \multicolumn{2}{|c|}{$\mathrm{Cu}$} \\
\hline & $\min$ & maks & $\min$ & maks & $\min$ & maks & $\min$ & maks & $\min$ & maks & $\min$ & maks \\
\hline Erdek Körfezi (Bu çalışma) & 21 & 430 & 15 & 36 & 3 & 5,3 & 4 & 25 & 48 & 88 & 10 & 20 \\
\hline Erdek Körfezi (Balkıs ve Çağatay, 2001) & 11 & 238 & 34 & 272 & 6 & 29 & $\mathrm{X}$ & $\mathrm{X}$ & 19 & 61 & 3 & 52 \\
\hline Bandırma Körfezi (Mülayim vd., 2012) & 3,2 & 229 & 25 & 80 & $\mathrm{X}$ & $\mathrm{X}$ & $\mathrm{X}$ & $\mathrm{X}$ & 17 & 35 & 0,008 & 27 \\
\hline Gemlik Körfezi (Ünlü vd., 2008) & 71 & 181 & 88 & 185 & 13 & 24 & $\mathrm{X}$ & $\mathrm{X}$ & $<0,1$ & 67 & 22 & 58 \\
\hline İzmit Körfezi (Pekey, 2006) & 38,9 & 112,4 & 440 & 1900 & $\mathrm{X}$ & $\mathrm{X}$ & 13,5 & 28,2 & 55,2 & 172 & 24,5 & 102,4 \\
\hline İzmir Körfezi (Atgın vd., 2000) & 208 & 308 & 99 & 260 & $\mathrm{X}$ & $\mathrm{X}$ & 25 & 30 & 36 & 62 & 32 & 70 \\
\hline Ortalama Şeyl (Krauskopf, 1979) & \multicolumn{2}{|c|}{100} & \multicolumn{2}{|c|}{80} & \multicolumn{2}{|c|}{20} & \multicolumn{2}{|c|}{6,6} & \multicolumn{2}{|c|}{20} & \multicolumn{2}{|c|}{57} \\
\hline
\end{tabular}

$\mathrm{X}$ : sonuç yok, min: minimum, maks: maksimum; X: not determined, min: minimum, maks: maximum 
Gönen Nehri önünden alınan GD1 karot çökeli çeşitli antropojenik kökenli kirleticiler ile zenginleştiği ICP-MS ağır metal analiz sonucunda ortaya çıkarılmıştır. Fakat ağır metal kirlilik boyutu diğer körfezlere (İzmit ve Gemlik) kıyasla daha düşüktür. Karotun üst seviyesi $(0-12 \mathrm{~cm})$ ortalama $\mathrm{EF}$ sonucuna göre $\mathrm{Cr}$, $\mathrm{As}$ ve $\mathrm{Pb}$ ile önemli derecede zenginleşmiştir. Arsenik ve $\mathrm{Pb}$ de karot boyunca gözlenen yüksek EF değerler (As:4,8, $\mathrm{Pb}: 12,2)$ kirlilik kaynağının sadece antropojenik kaynaklı olmadığı bunun yanında litojenik kaynaklı zenginleşmenin olduğu çevre kayaçların jeolojisi ile açıklanmaktadır. Karot çökelinin üst seviyesinde Cr'daki yüksek değerler deri işletme tesislerin atık sularından kaynaklanmaktadır. Erdek Körfezi çökelleri Co ve $\mathrm{Cu}$ ağır metallerince düşük derecede zenginleşirken, Zn ile karotun üst k1smında birkaç seviyede (12,5 ve 27,5 cm'lerde) orta derecede bir zenginleşme görülmektedir.

\section{EXTENDED SUMMARY}

This study investigates GD1 core sediment that was recovered from Erdek Gulf at -16 m water depth. We examined the heavy metal pollution history of sediments with anthropogenic and/or natural origin pollutant source. The pollution level in the region was determined by analysis of heavy metals (Cu, $\mathrm{Pb}, \mathrm{As}, \mathrm{Zn}, \mathrm{Cr}$ and $\mathrm{Co})$, grain size and total organic carbon (TOC) contents. Many researchers have investigated the metal distribution in Erdek Gulf surface sediments (Balkıs and Çağatay, 2001; Mülayim et al., 2012; Yümün et al., 2019) but this paper is the first study in the literature to reveal the historical heavy metal pollution in Erdek Gulf. Erdek Gulf is located in southwest Marmara Sea, with an average and maximum depth of around 34 and $55 \mathrm{~m}$, respectively. Karabiga and Gönen rivers are the major drainage systems that receive pollution load from domestic, industries (ceramic factories and leather industry) and agricultural waste water in Gönen and Biga towns and drain into the Marmara Sea. According the metal results, average $\mathrm{Cu}, \mathrm{Pb}, \mathrm{Zn}, \mathrm{Cr}$ and $\mathrm{Co}$ values through the core are 16, 68, 10, 26, 111 and $4 \mathrm{mg}^{\mathrm{kg}} \mathrm{kg}^{-1}$, respectively. The mean distribution of gravel, sand, silt and clay are 0.1, 1, 28.5 and $70.4 \%$ respectively. TOC content values ranged between 0.5 and $1.9 \%$. The upper part $(0-50 \mathrm{~cm})$ of the GD1 contains higher metal values than the lower part, which we might infer to be the presence of anthropogenic input. This idea is also supported by Sarl et al. (2018). Mean EF values show that the upper part $(0-12 \mathrm{~cm})$ of core sediment was significantly contaminated by $\mathrm{Cr}$, As and $\mathrm{Pb}$. The study area was not contaminated with $\mathrm{Co}, \mathrm{Cu}$ and $\mathrm{Zn}$. There are many $\mathrm{Pb}, \mathrm{Cu}, \mathrm{Fe}, \mathrm{Hg}$, and $\mathrm{Zn}$ mineral deposits and zones around Biga, Çan and Gönen towns and mafic-ultramafic rocks with high background values for $\mathrm{Ni}, \mathrm{Cr}$, and Co (Çăgatay et al., 2006). It is known that Karabiga and Gönen rivers transport these detritus materials into the Erdek Gulf. We can say that increasing metal contents are due not only to anthropogenic origin but also detritus inputs. The moderate Pearson correlation observed between $\mathrm{Cr}$ and $\mathrm{Al}(\mathrm{r}=0.6)$ shows that detrital materials have the effect of increasing the Cr element.

\section{ORCID}

Tuğçe Nagihan Arslan Kaya (D https://orcid.org/0000-0003-2655-1436 Erol Sarl (D) https://orcid.org/0000-0002-4037-9305

Mehmet Ali Kurt (D) https://orcid.org/0000-0001-7255-2056

Dursun Acar D https://orcid.org/0000-0003-3336-1534

\section{DEĞIINILEN BELGELER / REFERENCES}

Akkaya, E., 2004. Marmara Denizi'nin mevcut kirlenme durumu ve çözüm önerileri. 1. Ulusal Çevre Kongresi, 13-15 Ekim 2004, Sivas.

Akyüz, H.S., 1995. Manyas-Susurluk-Kepsut (Balıkesir) civarının jeolojisi. İstanbul Teknik Üniversitesi, Fen Bilimleri Enstitüsü, İstanbul, Doktora Tezi, $202 \mathrm{~s}$ (yayımlanmış).

Akyüz, T., Mukhamedshina, N., Akyuz, S., Sarı, E., Mirsagatova, A.A., 2007. Toxic and trace element analysis of surface sediments from the Gulf of Saros by INAA and XRF methods. Journal of 
Radioanalytical and Nuclear Chemistry, 273 (3), 747-751.

Amin, B., Ismail, A., Arshad, A., Yap, C.K., Kamarudin, M.S., 2009. Anthropogenic impacts on heavy metal concentrations in the coastal sediments of Dumai, Indonesia. Environmental Monitoring and Assessment, 148, 291-305.

Atgın, R.S., El-Agha, O., Zararsız, A., Kocataş, A., Parlak, H., Tuncel, G., 2000. Investigation of the sediment pollution in İzmir Bay: Trace elements. Spectrochimica Acta Part B: Atomic Spectroscopy, 55 (7), 1151-1164.

Balkıs, N., Çağatay, M.N., 2001. Factors controlling metal distributions on the surface sediments of the Erdek Bay, Sea of Marmara, Turkey. Environment International, 27 (1), 1-13.

Çağatay, M.N., Balkıs, N., Sancar, Ü., Çakır, Z., Yücesoy, F., Eryılmaz, M., Sarı, E., Erel, L., Akçer, S., Biltekin, D., 2006. Marmara Denizi çökel jeokimyası atlası, TÜBITTAK Projesi, 103Y053, İstanbul (Yayınlanmış).

Çağatay, M.N., Görür, N., Polonia, A., Demirbağ, E., Sakinç, M., Cormier, M.H., Capotondi, L., McHugh, C.M.G., Emre, Ö., Eriş, K., 2003. Sea-level changes and depositional environments in the Izmit Gulf, eastern Marmara Sea, during the late glacial-Holocene period. Marine Geology, 202, 159-173.

Çağatay, M.N., Keigwin, L.D., Okay, N., Sarı, E., Algan, O., 2002. Variability of clay-mineral composition on Carolina Slope (NW Atlantic) during marine isotope stages 1-3 and its paleoceanographic significance. Marine Geology, 189 (1-2), 163-174.

EİE. 1993. Türkiye akarsularında sediment gözlemleri ve sediment taşınım miktarları. Elektrik İşleri Etüd İdaresi Genel Müdürlüğü, No: 93-59, Ankara (yayınlanmış).

European Commission, 2007, MET referans doküman1 (BREF), (http:// eippcb.jrc.ec.europa.eu/), 30 Nisan 2019.

Galehouse, J.S., 1971. Sedimentation Analysis, (Procedures in sedimentary petrology, Editör: Carver, R.E., Wiley-Interscience, New York, 6994.

Gaudette, H.E., Flight, W.R., Tonner, L., Folger, D.G., 1974. An inexpensive titration method for the determination of organic carbon in recent sediments. Journal of Sedimentary Research, 44, 249-253.

Hall,, M., 2014. Ergene Nehri'nin Ege Denizi'ne Olan Kirlilik Etkisinin Güncel Çökel Jeokimyası ve Sedimantolojik Yöntemlerle Araştırılması. İstanbul Üniversitesi Deniz Bilimleri ve İşletmeciliği Enstitüsü, Yüksek Lisans Tezi, 86 s., (yayımlanmamış).

Hallı, M., Sarı, E., Kurt, M.A., 2014. Assessment of arsenic and heavy metal pollution in surface sediments of the Ergene River, Turkey. Polish Journal of Environmental Studies, 1581-1590.

Karabulut, A.T., 2004. Biga Yarımadasinda Jura Öncesi Muhtemel Bir Ofiyolit Topluluğu. İstanbul Teknik Üniversitesi, Yüksek Lisans tezi, 41 s., (yayınlanmış).

Karbassi, A.R., Monavari, S.M., Bidhendi Gh. R., Nouri, J., Nematpour, K., 2008. Metal pollution assessment of sediment and water in the Shur River. Environmental Monitoring and Assessment, 147, 107-116.

Krauskopf, K.B., 1979. Introduction to Geochemistry, 2nd edition. International series in the Earth and Planetary Sciences. McGraw-Hill, New York, 617 s.

Loring, D.H., Rantala, R.T.T., 1992. Manual for the geochemical analyses of marine sediments and suspended particulate matter. Earth-Science Reviews, 32 (4), 235-283.

Malvandi, H., 2017. Preliminary evaluation of heavy metal contamination in the Zarrin-Gol River sediments, Iran. Marine Pollution Bulletin, 117, 547-553.

McManus, J., 1988. Grain size determination and interpretation, (Techniques in Sedimentology, Editör: Tucker, M.,). Blackwell Scientific Publication, Oxford, 63-85.

Mohsen, M., Wang, Q., Zhang, L., Sun, L., Lin, C., Yang, H., 2019. Heavy metals in sediment, microplastic and sea cucumber Apostichopus japonicas from farms in China. Marine Pollution Bulletin, 143, 42-49.

Mülayim, A., Balkıs, N., Balkıs, H., Aksu, A., 2012. Distributions of the metals in the surface sediments of the Bandırma and Erdek Gulfs, Marmara 
Sea, Turkey. Toxicological and Environmental Chemistry, 94 (1), 56-69.

Sakan, S.M., Dordevic, D.S., Monojlovic, D.D., Predrag, P.S., 2009. Assessment of heavy metal pollutants accumulation in the Tisza river sediments. Journal of Environmental Management, 90, 3382-3390.

Sar1, E., 2008. Source and distribution of heavy metals in river sediments from the southern drainage basin of the Sea of Marmara, Turkey. Fresenius Environmental Bulletin, 17 (12), 2007-2019.

Sarı, E., Ünlü, S., Apak, R., Balcı, N., Koldemir, B., 2013. Evaluation of contamination by selected elements in a Turkish Port. Polish Journal of Environmental Studies, 22, 841-847.

Sarı, E., Çağatay, M.N., Acar, D., Belivermiş, M., Kılıç, Ö., Arslan, T.N., Tutay, A., Kurt, M.A., Sezer, N., 2018. Geochronology and sources of heavy metal pollution in sediments of Istanbul Strait (Bosporus) outlet area, SW Black Sea, Turkey. Chemosphere, 205, 387-395.

Sutherland, R.A., 2000. A comparison of geochemical information obtained from two fluvial bed sediment fractions. Environmental Geology, 39 (3-4), 330-341.

Tchounwou, P.B., Yedjou, C.G., Patlolla, A.K., Sutton, D.J., 2012. Heavy metals toxicity and the environment. EXS 101 (101), 133-164.

Ternek, Z., Erentöz, C., Pamir, H.N., Akyürek, B., 1987. 1/500.000 ölçekli Türkiye Jeoloji Haritas1, İstanbul Paftası. Maden Tetkik ve Arama Genel Müdürlüğü Yayınları, Ankara.
Ünlü, S., Topçuoğlu, S., Alpar, B., Kırbaşoğlu, C., Yllmaz, Y.Z., 2008. Heavy metal pollution in surface sediment and mussel samples in the Gulf of Gemlik. Environmental Monitoring and Assessment, 144, 169-178.

Ünlüata, Ü., Oğuz, T., Latif M.A., Özsoy, E., 1990. On The Physical Oceanography of The Turkish Straits. The Physical Oceanography of the Sea Straits. NATO/ASI Series, 25-60.

Yıldız, M., Gürkan, M.O., Turgut, C., Kaya, Ü., Ünal, G., 2005. Tarımsal savaşımda kullanılan pestisitlerin yol açtığı çevre sorunları (Environmental problems of pesticides used in plant protection), VI. Türkiye Ziraat Mühendisliği Teknik Kongresi, 3-7 Ocak 2005, TMMOB Ziraat Mühendisleri Odas1, Ankara.

Yüce, H., Türker, A., 1991. Marmara Denizi'nin fiziksel oşinografik özellikleri ve Akdeniz suyunun Karadeniz'e girişi. Uluslararası Çevre Sorunları Sempozyumu Tebliğleri, İstanbul Marmara Rotary Kulübü, İstanbul, 284-303.

Yümün, Z.Ü., Kam, E., Önce, M., 2019. Analysis of toxic element with ICP-OES and libs methods in marine sediments around the sea of Marmara in Kapıdağ Peninsula. Journal of Engineering Technology and Applied Sciences, 4 (1), 43-50. 